\title{
Closed-loop and congestion control of the global carbon-climate system
}

\author{
Carlos A. Sierra ${ }^{1}$ (D) . Holger Metzler ${ }^{1}$ (D) . Markus Müller ${ }^{1}$ (D) Eurika Kaiser $^{2}$ (D)
}

Received: 22 July 2019 / Accepted: 5 January 2021 / Published online: 11 March 2021

(C) The Author(s) 2021

\begin{abstract}
The global carbon-climate system is a complex dynamical system with multiple feedbacks among components, and to steer this system away from dangerous climate change, it may not be enough to prescribe action according to long-term scenarios of fossil fuel emissions. We introduce here concepts from control theory, a branch of applied mathematics that is effective at steering complex dynamical systems to desired states, and distinguish between open- and closed-loop control. We attempt (1) to show that current scientific work on carbon-climate feedbacks and climate policy more closely resembles the conceptual model of open- than closed-loop control, (2) to introduce a mathematical generalization of the carbon-climate system as a compartmental dynamical system that can facilitate the formal treatment of the closed-loop control problem, and (3) to formulate carbon-climate control as a congestion control problem, discussing important concepts such as observability and controllability. We also show that most previous discussions on climate change mitigation and policy development have relied on an implicit assumption of open-loop control that does not consider frequent corrections due to deviations of goals from observations. Using a reduced complexity model, we illustrate that the problem of managing the global carbon cycle can be abstracted as a network congestion problem, accounting for nonlinear behavior and feedback from a global carbon monitoring system. As opposed to scenarios, the goal of closed-loop control is to develop rules for continuously steering the global carbon-climate system away from dangerous climate change.
\end{abstract}

Keywords Global carbon cycle · Nonlinear control · Climate policy ·

Dynamical systems · Earth system dynamics

Carlos A. Sierra

csierra@bgc-jena.mpg.de

Eurika Kaiser

eurika@uw.edu

1 Max Planck Institute for Biogeochemistry, Hans-Knöell-Str. 10, 07745 Jena, Germany

2 Mechanical Engineering Department, University of Washington, 3900 E Stevens Way NE, Seattle, WA 98195, USA 


\section{Introduction}

Limiting the increase in global average temperatures well below $2{ }^{\circ} \mathrm{C}$, as expressed in the Paris Agreements, implies that humanity can tackle the enormous challenge of managing the global carbon cycle and Earth's energy balance (Caldeira et al. 2013; Sundquist et al. 2013; Steffen et al. 2018). This is arguably one of the most complex political, economic, and scientific problems that humanity will have to deal with in the twenty-first century. There is fortunately a tremendous amount of work in defining policy and economic instruments for mitigation and adaptation to climate change, in quantifying carbon sources and sinks in natural reservoirs for carbon sequestration purposes, and in developing technologies for alternative energy sources and for geo-engineering. Despite attempts for conceptual synthesis (e.g., Pacala and Socolow 2004; Long and Shepherd 2014; Steffen et al. 2018), these activities are not necessarily well articulated, and an analytical framework that anchors all different forms of climate action may help to deal with this problem more effectively.

Managing the global carbon-climate system to steer Earth to a desired state is in essence a control engineering problem. Control theory provides an appropriate analytical framework, with concepts and mathematical tools to steer complex dynamical systems to desired states. It has demonstrated successes in a wide range of disciplines and problems such as aerospace, robotics, biomedical engineering, autonomous transportation, treatment of diseases (drug therapy, neurological disorders), organismal biology (flight behavior, locomotion), among others (Ogata and Yang 2002; Khalil 1996; Aström and Murray 2010; Sastry 2013; Stengel 2012). Modern control theory concepts are already being applied in climate science, particularly in the design of geo-engineering methods for solar radiation management (MacMartin and Kravitz 2019), and they have a large potential for application in a variety of problems for climate change mitigation such as the management of the global carbon cycle.

In the process of control design for complex dynamical systems, two main strategies can be adopted (Ogata and Yang 2002): open- or closed-loop control (also known as precomputed versus feedback control, Fig. 1). In the open-loop strategy, a control law is precomputed and implemented under the assumption that this prescription will steer the system to the desired state. In the closed-loop case, observations are taken to adapt the action, and correct for random perturbations and deviations due to noise or model representation uncertainty (Sontag 1998; Aström and Murray 2010).

With some exceptions, current scientific work on carbon-climate feedbacks as well as the development of policy instruments for climate change mitigation, resemble better the openthan the closed-loop model (Fig. 1). The science of carbon-climate feedbacks is strongly dominated by scenario-based analyses where long-term emission scenarios are used to predict climate effects and impacts (e.g., IPCC 2018). The results from these scenariobased impacts are then an important instrument for the design of climate change mitigation policies that aim to follow a specific scenario pathway (Morgan and Keith 2008).

Previous modeling work on the design of solar radiation management methods clearly shows that the closed-loop control strategy is not only effective at achieving climate mitigation goals but also necessary to deal with uncertainties, unexpected change, and nonlinear behavior not necessarily included in Earth system models (Jarvis et al. 2009; Kravitz et al. 2014; Bonetti and McInnes 2018; MacMartin and Kravitz 2019). We believe there are enormous opportunities to apply control theory methods to climate change mitigation, particularly for designing and deploying methods that aim at managing the global carbon cycle (Jarvis et al. 2008; Jarvis et al. 2009).

In this manuscript, we aim at formally posing the problem of steering the global carbonclimate system to a desired state as a closed-loop control problem, with particular emphasis 


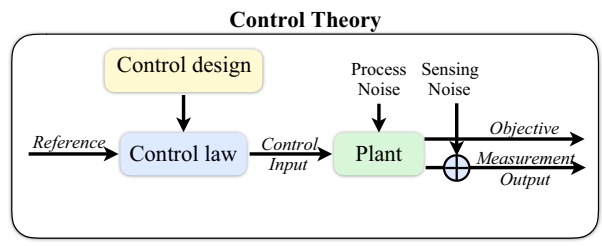

(a) Open-loop control (pre-computed)

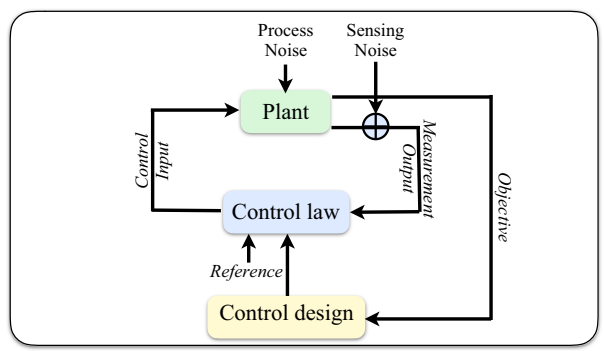

(b) Closed-loop control (feedback)

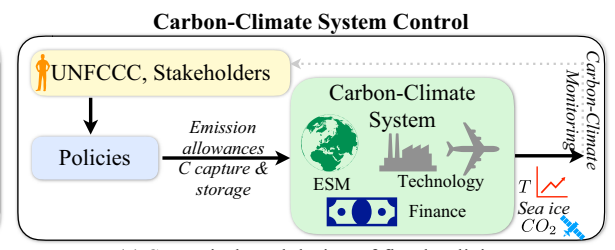

(c) Scenario-based design of fixed policies

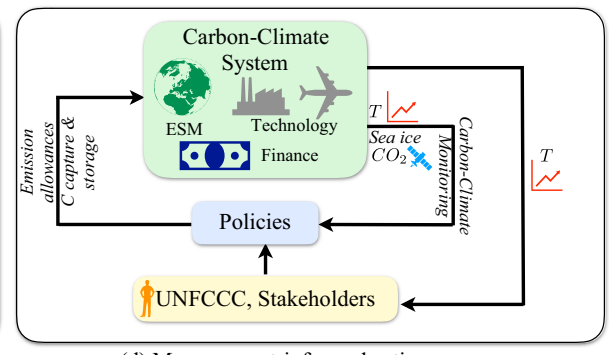

(d) Measurement-informed action

Fig. 1 Two different strategies for control of dynamical systems (left) and their analogous concept for the management of the carbon-climate system (right). a Traditional representation of an open-loop (precomputed) controller. b Traditional representation of a closed-loop (feedback) controller. c Scenario-based design of policies for climate change mitigation in analogy to open-loop control. d Measurement-informed design and evaluation of policies for climate change adaptation in analogy to closed-loop control

on global carbon management. For this purpose, we first review previous work on control theory applied to climate science, then propose a mathematical abstraction of the global carbon-climate system to make the problem more tractable, and introduce a set of concepts from control theory and draw their analogy in terms of global carbon management. We propose formulating the problem of stabilizing atmospheric $\mathrm{CO}_{2}$ as a congestion control problem, and introduce a simple illustrative example, aimed at setting emission allowances taking into account the potential for saturation of natural carbon sinks (Canadell et al. 2007; Le Quéré et al. 2008).

\section{Control theory concepts in climate change mitigation}

Control theory is a broad field with multiple concepts, strategies and techniques, with some methods employing optimization ideas. Although ideas about optimization of costs and benefits of climate change mitigation have a long history in climate science and policy, the application of modern control theory is much more recent. Optimization concepts played a significant role in the development of Integrated Assessment Models (IAMs) (Nordhaus 1975; Weyant 2017). These models generally produce optimal prescriptions that can be used for policy response. At the heart of these models is the idea that social welfare can be maximized by searching a space of future trajectories of emissions with related social costs due to climate impacts (Ackerman et al. 2009). This benefit-cost optimization approach produces time trajectories of emissions useful for policy development, but do not include a formal treatment of feedback and correction based on observations. A new generation of models are now coupling ESMs with IAMs (Collins et al. 2015; Thornton et al. 2017), which explicitly consider feedbacks between the physical climate, biogeochemical cycles, 
and anthropogenic emissions, but these feedbacks are not evaluated in the formal control sense despite their large potential to do so.

Schellnhuber and Kropp (1998) introduced concepts of feedback control engineering using the term "geocybernetics" in reference to the field of cybernetics that studied feedback mechanisms in natural systems and machines. These authors devised intuitive ideas about the need to exert some control on natural systems to achieve sustainable development at the Earth system level, but did not use the mathematical formalisms of control theory.

More recently, there have been major advancements in applying modern control theory to the problem of solar radiation management (SRM) (Kravitz et al. 2014; MacMartin et al. 2014a; MacMartin et al. 2014b; Cao and Jiang 2017; Bonetti and McInnes 2018; MacMartin and Kravitz 2019), and carbon dioxide removal (CDR) (Jarvis et al. 2008; Jarvis et al. 2009). These studies explicitly account for deviations of the system from the desired state, and design a control law that quantifies the amount and timing of SRM or CDR based on continuous observations of the dynamics of the system.

Studies on SRM have been successful at developing control laws that explicitly address issues of model uncertainty (Kravitz et al. 2014; MacMartin et al. 2014b; Jackson et al. 2015), can deal with inter-hemispheric gradients in climate (Kravitz et al. 2016; Bonetti and McInnes 2018), and consider multiple control objectives with spatial arrangements of actuators, e.g., for effective injections of aerosol in the stratosphere (Kravitz et al. 2017a; Kravitz et al. 2017b; MacMartin et al. 2017; Bonetti and McInnes 2018). Most of these previous studies have been based on simple linear systems, although more recently the control law has been tested with more complex climate models (MacMartin et al. 2014a; Kravitz et al. 2017a; MacMartin et al. 2017).

Only a few studies have used coupled carbon-climate models (Matthews and Caldeira 2008; Cao and Jiang 2017), which is surprising given the large potential for the use of control theory in managing the global carbon cycle. In contrast to SRM, which humans may decide to never implement due to unknown environmental consequences, our society is already well advanced in implementing policies to either reduce emissions or store carbon in long-term sinks. To our knowledge, policies developed under the United Nations Framework Convention on Climate Change (UNFCCC), and other policy frameworks for emission trading, have not been based on formal concepts from closed-loop control, and very few scientific studies have made use of these concepts for exploring feedback control of the global carbon cycle.

Some of the limitations to implement feedback control for managing the global carbonclimate system may have to do with the complexity of the system itself and the models used to represent it. In the following, we propose a generalization of the global carbonclimate system that can deal with models of any level of complexity. We expect that with this generalization, closed-loop control problems would be easier to study and to implement in large ESMs.

\section{A compact mathematical abstraction of the global carbon-climate system}

The state of the global carbon-climate system at any given time $t \in \mathbb{R}$ can be expressed as vector $x \in \mathbb{R}^{n}$, whose elements are stocks of carbon and temperature in multiple Earth system reservoirs. The state $x(t)$ as a function of time can be expressed mathematically as the result of a mapping $\mathscr{F}:\left(x_{0}, v\right) \mapsto x$ from the combination of the initial conditions $x_{0}:=x\left(t_{0}\right)$ and a vector of driving signals as functions of time $v(t)$. For example, we can 
think about $\mathscr{F}$ as an Earth system model that takes the initial state $x_{0}$ and a vector of time dependent driver variables $v(t)$ defined on a time interval $\mathbb{T}=\left[t_{0}, t_{\max }\right]$ and yields the whole trajectory of the state $x(t)$ for $t \in \mathbb{T}$ of the global carbon-climate system.

Although the mapping $\mathscr{F}$ could be expressed in more general ways, we restrict ourselves here to the case of an initial value problem for the coupled system of ordinary differential equations describing the evolution of carbon in Earth's reservoirs $C(t)$ and surface temperature $T(t)$ in block matrix structure as

$$
\dot{x}=\left(\begin{array}{c}
\dot{C} \\
\dot{T}
\end{array}\right)=\left(\begin{array}{c}
\mathbf{B}(C, T, t) \cdot C+s(t) \\
g(C, R, t)
\end{array}\right) .
$$

The global carbon cycle is represented in the first line as a non-autonomous (time dependent) nonlinear compartmental system (Sierra et al. 2018) that is influenced nonlinearly by Earth's surface temperature. The compartmental matrix $\mathbf{B}$ accounts for all process and transfer rates among system compartments, while the vector $s$ accounts for all mass inputs into the system. This compartmental system represents the active part of the carbon cycle (atmosphere, terrestrial biosphere, and the ocean), and it is open with respect to ocean sediments and geological reservoirs (Rodhe and Björkström 1979; Metzler et al. 2018). The surface temperature function $g$ depends on solar radiation and other agents of radiative forcing $R$ as well as on the state of the carbon cycle (Hasselmann 1976; Fredriksen and Rypdal 2017; Cox et al. 2018).

Equation (1) is a very general representation of carbon-climate models of different levels of complexity and sophistication, representing various coupled carbon-climate feedbacks (e.g., models in Friedlingstein et al. 2014). Its dimension $n$ can range from $n<10$ to $n>10^{7}$ state variables, depending on the level of detail of the chosen model (Raupach 2013).

The compartmental structure of the global carbon system imposes very important mathematical restrictions on the dynamical system (1) (Anderson 1983; Jacquez and Simon 1993). The subsystem regarding the global carbon cycle is mass balanced; i.e., carbon is neither produced or destroyed inside the system. This is guaranteed by the compartmental structure of the matrix $\mathbf{B}$, which meets three important characteristics:

(i) All diagonal entries are non-positive,

(ii) All off-diagonal entries are non-negative, and

(iii) All column sums are non-positive.

Diagonal entries describe the total (to other pools and to outside the system) instantaneous loss rates of the compartments, while off-diagonal entries are instantaneous flow rates between compartments. The column sums represent the compartments' external output rates and their non-positivity guarantees that only mass can leave the system if it had previously entered it. The compartmental structure of $\mathbf{B}$ and the non-negativity of the external input vector $s$ ensure that the trajectory $C(t)$ remains in the non-negative orthant, given that it started there.

Autonomous mass-balanced systems can have multiple equilibria, one of which is usually regarded the desired operational point of the system. This particular equilibrium is locally asymptotically stable and consequently an open-loop control might be sufficient. Nevertheless, large perturbations may drive the system away to a less desirable stable equilibrium or even toward a catastrophic state. Closed-loop control can help mitigate or prevent such behavior. Simple closed-loop control laws based on the mass-balance property of the compartmental system can possibly control the total mass of the system or even keep the system's state inside a preferable invariant set. If such a control law is independent of the 
compartmental matrix $\mathbf{B}$, then the feedback stabilization is robust against model uncertainties about flux rates as long as the system satisfies the properties of positivity and mass conservation, i.e., the system is compartmental. Furthermore, control laws that rely on physically based Lyapunov functions can ensure global asymptotic stability of the controlled system (Bastin and Praly 1999; Bastin 1999).

\section{A control theory approach to manage the global carbon-climate system}

To pose the control problem of the global carbon-climate system, we expand now the representation of our system to allow for the inclusion of control signals $u(t)$ and noise $\boldsymbol{\mu}(t)$ (Stengel 2012). Our previous mapping $\mathscr{F}$ acquires two new arguments:

$$
\mathscr{F}_{c}: \quad\left(x_{0}, v, u, \mu\right) \longmapsto x .
$$

This function $\mathscr{F}_{c}$ may be very complicated, capturing the non-autonomous, nonlinear, multi-scale, and stochastic nature of the climate system. While $v(t)$ still represents external drivers that influence the behavior of the system, e.g., changes in solar activity or Earth's rotation, we now isolate in $u(t)$ variables that are subject to control such as fossil fuel emissions and emission reductions, carbon sequestration in biological and geological reservoirs, and solar radiation management. We also separate process noise and model uncertainties as the vector-valued function $\mu(t)$.

Typically, we do not know the complete state $x(t)$ of the system, and only have access to a limited set of measurements or observations $y(t)$ to gather knowledge of the system. These measurements are collected from an observation network and provide information on a set of variables such as air surface temperature, atmospheric carbon dioxide concentrations, and gross primary production. We introduce now a mapping from the system's state to observations

$$
\mathscr{G}: \quad(x, u, w) \longmapsto y,
$$

which may depend further on the inputs $u(t)$, and it is typically affected by measurement noise $w(t)$. Both $\mathscr{F}_{c}$ and $\mathscr{G}$ together represent our plant (Fig. 1), that is altered by inputs $u(t)$ and observed through outputs $y(t)$. Thus, the challenge society faces is to determine what action $u(t)$ needs to be taken during the upcoming years, e.g., for $t \in[2020,2100]$, to prevent dangerous warming.

The design and selection of strategies to achieve a particular goal is a core purpose of control theory. It aims at providing methods and tools to systematically analyze the system's behavior, formulate the control problem, and construct control strategies (Sastry 2013; Stengel 2012) to achieve a desirable dynamic response of the system (Table 1). Moreover, this theory provides means to formally address questions such as the following.

What variables and parameters of the system should be controlled because they are most effective? Are current mitigation strategies sufficient to control the system? It is important to quantify the potential benefit of different climate response strategies, e.g., carbon vs solar radiation management, which may inform about which strategy should deserve increased attention. At a different level, it is also possible to evaluate different methods for CDR such as afforestation, bioenergy, or direct air capture. For example, one can quantify what combination of methods is feasible, at what scale are they required, and what methods have the largest potential according to different geographical characteristics where they can be implemented. 
Table 1 Equivalence between specific concepts in control theory and their meaning for managing the global carbon-climate system

Control theory concept Earth system analogous concept or implication

Open-loop controller

Set of policies to keep atmospheric $\mathrm{CO}_{2}$ and mean surface temperature at a certain predefined target, informed by scenario-based modeling without feedback from observations. Policies are prescribed for long-term horizons. This is the approach followed by Integrated Assessment Models where the cost of climate change action are optimized with respect to climate-related damages.

Closed-loop controller

Adaptive management of the carbon-climate system. Set of policies to keep atmospheric $\mathrm{CO}_{2}$ or mean surface temperature at a certain predefined target, allowing for feedback between observed outcomes that may result in corrections of previous policies.

Observability

Ability to infer the state of the carbon-climate system with knowledge from a limited set of observations. For the global carbon cycle, observability can be expressed as the capacity to infer the size of other pools and fluxes from observations of a limited set of variables such as atmospheric $\mathrm{CO}_{2}$ concentrations and net fluxes among main carbon reservoirs.

Controllability

Ability to steer the carbon-climate system to a desired state, and as such crucial for effective control design.

Nonlinear control

Branch of control theory that can deal with nonlinear systems. Since the global carbon-climate system has multiple feedbacks that result in nonlinear interactions among system components, nonlinear control is critical to control the system in a desired manner.

System representation and identification

Mathematical or algorithmic representation of the global carbon-climate system. Earth system models are representations based on physical and biological laws. System identification attempts at producing mathematical models based on observations. When observations are limited and the system is highly complex, the system may be non-identifiable.

Control law

Rules based on a mathematical model that prescribe the set of actions to take in order to steer the carbon-climate system to a desired state. Policies to limit carbon emissions, solar radiation management, or carbon sequestration can be considered control laws.

Control design

Set of strategies to be considered that would lead to a specific control law. For example, strategies can be designed that steer the carbon-climate system to a particular state (e.g., $350 \mathrm{ppm}$ ) or to follow a particular trajectory in the atmospheric $\mathrm{CO}_{2}$-temperature space.

Sensor

Global monitoring system of the carbon-climate system that provides information on a set of variables such as surface temperatures, albedo, atmospheric $\mathrm{CO}_{2}$, and gross primary production.

Actuator

Instruments or means that implement the control law by modifying elements of the carbon-climate system. For instance, solar radiation management via injection of aerosols into the atmosphere can be interpreted as a form of actuation.

Are current monitoring systems sufficient to observe the state of the carbon-climate system? How do we estimate the state from collected measurements? Where should we place new monitoring infrastructure? The state of the Earth system is currently assessed by analysis of data collected from various satellite- and station-based monitoring systems, e.g., temperature, precipitation, cloud coverage, and ice coverage, in order to inform about Earth's climate in general and consequences of its change specifically, such as droughts, weather extremes, sea-level rise. However, the employed monitoring systems have not been 
initially introduced with all these tasks in mind; in contrast, they have been developed over time as sensing capabilities as well as monitoring demands grew. There are increasing constraints set on new sensing systems to be deployed, including their general usefulness for long-term monitoring and forecasting and their economic costs (Weatherhead et al. 2018). Thus, a systematic quantification of their capabilities and potential is of vital importance.

Can we ensure (and how) that the employed mitigation strategies are robust with respect to uncertainties (model discrepancies, unpredictable environmental factors, etc.)? The control of the global carbon-climate system is a tremendously challenging problem. Climate models are high-dimensional, nonlinear, and multi-scale systems, which are in general hard to analyze and, especially, to control. Moreover, while Earth system models have been improving significantly, they remain imperfect. While available monitoring systems are extensive, they are limited. Given these limitations it is important to quantify and constrain the potential(ly adverse) impact of mitigation strategies. Some of the aspects will be discussed in the following sections.

\subsection{The closed-loop control problem}

The concept of adaptive management in environmental sciences is closely related to the concept of closed-loop control (Walters and Hilborn 1978; Anderies et al. 2007; Vardas and Xepapadeas 2010; Levin et al. 2013), where it is generally contrasted with the concept of open-loop control.

Open-loop control, also referred to as feedforward or precomputed control, is performed in a predefined manner independent of the changes of the system state. It is a very useful and effective method if the general input-output behavior (as opposed to the actual state) of the system is well characterized and does not change over time, or due to the control itself. As previously mentioned, we believe that current approaches to carbon-climate management can be interpreted as belonging to open-loop control (Fig. 1). Successful open-loop strategies require an accurate description of the real-world system via the model $\mathscr{F}$, and uncertainties, unrepresented processes or system changes (as the control itself may modify the system) are generally not accounted for. Thus, the measurement output has no influence on the control input. In the context of climate science and policy, open-loop control strategies result in production of scenarios or long-term policies that are followed without feedback from observations.

Alternatively, in closed-loop or feedback control (Skogestad 2007; Aström and Murray 2010) the controller is informed by measurements and adapts accordingly. In particular, we are searching for a control law $\mathscr{K}$ (rules) that translates measurements $y(t)$ into a new action $u(t)$ :

$$
\mathscr{K}: \quad y \longmapsto u \text {. }
$$

The controller implements the action as prescribed by the control law through a so-called actuator. In the context of the global carbon-climate system, the actuator can be something abstract, such as the implementation of a law on how much emissions are allowed, or something more concrete, such as the deployment of a technology for SRM or CDR (Jarvis et al. 2008; Jarvis et al. 2009; MacMartin and Kravitz 2019). A measurement-informed feedback is essential for the mitigation of disturbances and to adapt to changing conditions of the system (e.g., parameter changes, external uncontrollable drivers of the system, delay in policy implementation, or unexpected system responses due to nonlinear feedbacks). The 
controller evaluates the response of the system to the control action and adjusts the next control action accordingly.

The carbon-climate system is highly nonlinear and non-autonomous, and current stateof-the-art models remain imperfect and suffer from misrepresentation and uncertainties requiring model revision strategies. There have been tremendous advances in climate and carbon monitoring systems in recent years (e.g., Le Quéré et al. 2018; Friedlingstein et al. 2019), which can be used to systematically adapt policies as new measurements become available. The largest benefits can be expected from closed-loop strategies. Instead of performing scenario analyses aiming at the implementation of fixed long-term policies (Morgan and Keith 2008), we propose to design adaptive policies that incorporate immediate feedback from the response of the system (Levin et al. 2013). This perspective assumes that we can evaluate the effectiveness of a policy at time scales faster than the time scales of political processes that produce these policies.

\subsection{Observability and controllability}

The characterization, modeling, and control of a dynamical system pose particular requirements on the monitoring network (sensors) and control implementations (actuators), each with their own respective capabilities and limitations (Stengel 2012; Sastry 2013). These include the ability to measure and estimate the state of the system, given constraints on the type, number and location of sensors. Analogous requirements can be posed for the control architecture, i.e., the type, number, and location of actuators necessary to manipulate the system in a desired manner.

Observability and controllability are two important concepts that are useful for the evaluation and decision-making process on sensing and control capabilities (Stengel 2012). In particular, observability describes the ability to reconstruct the state of the system from measurements. Controllability describes the ability of the actuator to manipulate the system state. As a consequence, observability determines the ability to design an estimator of the system state that reconstructs or estimates the full state from measurements, and analogously, controllability of a system determines the ability to design the control law $\mathscr{K}$. There exists a powerful mathematical framework to quantify these properties, e.g., as a binary decision (system is/is not observable/controllable) or to characterize the degree of observability/controllability. Further, these properties of a system are useful to inform the design and selection process for a particular set of sensors and actuators with desired capabilities. For instance, the controllability rank condition, introduced in the seminal work of Kalman et al. (1963), has been used by Bonetti and McInnes (2018) to determine the controllability of a linear representation of the climate system with respect to a different number of SRM actuators and their locations.

Given the vast and growing sensor network for monitoring the Earth's carbon-climate system, there is a large potential to systematically analyze and evaluate which variables need to be measured, what sensors are crucial for the estimation of the state of the global carbon-climate system, and whether current efforts are already sufficient. This is crucial for the development of existing and new sensor technologies given the constraints on financial, technical, and political instruments, and will guide the focus of society's efforts. Moreover, considering the pessimistic estimates for the rise of the global temperature over the coming years, it is critical to quantify the potential impact of current control mechanisms and the need and type of specific alternatives, so that implemented policies and control strategies can act with the required speed and strength at a minimum amount of time. 


\subsection{Control design and control law}

Control design is the task of determining a control law $\mathscr{K}$ that prescribes how measurements are mapped to control actions. The design of the control law typically involves some tuning, e.g., of parameters or the structure of the control law, by analyzing properties or observing the response of the system (Khalil 1996; Sastry 2013).

Much of previous work on closed-loop control in the context of controlling the climate or socio-ecological systems (Anderies et al. 2007; Jarvis et al. 2008; Kravitz et al. 2014; Bonetti and McInnes 2018; Cao and Jiang 2017; Kravitz et al. 2017a; Kravitz et al. 2017b) is focused on linear or linearized models and/or employs linear feedback control methods, in particular the proportional-integral (PI) controller and its variants. The PI controller has been successfully used in many applications. However, one of its major limitations is that it requires the system to remain close to its operating point, e.g., the point in the vicinity where the nonlinear system has been linearized. However, the global carbon-climate system is an inherently nonlinear system. Linearization around a particular operating point may destroy crucial nonlinear interactions, which are critical for the prediction task and may be exploited for control. Further, disturbances and uncertainties do have a large impact on the system and can lead to significant system changes rendering the controller invalid. More generally, as there are realistic climate models available, model-based control approaches seem promising and may have a larger impact. Jackson et al. (2015) provide a great example toward this direction by incorporating a simple model into the model-based control strategy that informs the forcing in the full-complexity model.

An essential aspect in many control strategies is the formulation and evaluation of a control objective, which can be a surprisingly difficult task. Often, we are not able to measure directly the control objective of interest, but instead need to use a proxy for it. The proxy must be chosen carefully as the control then aims to achieve a desirable value for the proxy itself. For instance, society is interested in keeping the rise of the global average temperature well below $2{ }^{\circ} \mathrm{C}$; however, a better proxy to achieve this goal may be to keep the average $\mathrm{CO}_{2}$ concentration in the atmosphere fixed at a certain value. Carbon dioxide is a well-mixed gas that shows less spatial and temporal variability than temperature, and can be consistently and accurately monitored from an observation network. Control of this proxy, however, is dependent on the level of uncertainty in climate sensitivity due to raising atmospheric $\mathrm{CO}_{2}$ (Knutti et al. 2017), changes in radiative forcing of other greenhouse gases, and long-term responses due to ocean circulation and thermal inertia. A more abstract review of the design process with respect to objective functions in the context of geo-engineering is provided in Kravitz et al. (2016). In general, the control objective is a measure of the performance of the controller and reflects a trade-off between multiple objectives, e.g., the error between the state of the system and the desired state and the cost to achieve its minimization. The control objective can be mathematically formalized as a cost function to be minimized or maximized and that may also penalize the control effort via $u(t)$ as determined by the control law $\mathscr{K}$ itself.

Control design involving objective functions is often formulated in the context of optimal control (Stengel 2012). Levin et al. (2013) provided a general introduction of optimal control and adaptive feedback strategies for socio-ecological systems. Optimal control has recently been used for resource management in socio-ecological systems (Anderies et al. 2007), where it has been compared with robust control methods. However, the employed model was a simple one-dimensional logistic-type model. More recently, Jackson et al. (2015) employed a receding-horizon model-predictive control strategy based on a reducedcomplexity model to control sea-ice extent in a high-complexity, full-scale model. Model 
predictive control (MPC) (Camacho and Alba 2013; Mayne et al. 2000) is an adaptive optimal control approach, which has gained increasing popularity over the last decade. MPC benefits from simple and intuitive tuning, the flexibility to incorporate arbitrary cost functions and constraints, and the ability to control a wide range of simple and complex phenomena, including systems with time delays, non-minimum phase dynamics, and instability. Low latency is crucial for robust control performance, as instabilities may arise from time delays between sensing and actuation. The adaptive and predictive nature of MPC, in contrast to, e.g., PID controllers, could prove here very useful in dealing with greenhouse gases that have long timescales in the atmosphere and require long simulations into the future to assess climate impacts. The most challenging part of MPC is the identification of a low-dimensional predictive model, which is separate from the actual control design. MPC has been shown to be robust with respect to model errors due to its receding horizon formulation (Kaiser et al. 2018). Especially in high-dimensional and multi-scale systems, where reliable low-order descriptions are difficult to obtain and where parameters vary or are affected by uncertainties, adaptive and tuning methods play a critical role.

There exist a multitude of adaptive control strategies that aim to achieve their control objective by continuously adjusting parameters based on the measured system output. Gainscheduling (Shamma and Athans 1990) allows one to generalize linear methods to nonlinear systems by considering a set of localized linear models and controllers, each defined for a particular operating point. In contrast, extremum-seeking control (Zhang and Ordóñez 2012) does not rely on a model and involves a perturbation-based scheme to manipulate generally nonlinear systems.

More broadly, closed-loop control comprises a large variety of strategies, including model-based (Stengel 2012; Sastry 2013) and model-free (Sutton and Barto 2018; Åström and Wittenmark 2013; Fleming and Purshouse 2002) (adaptive, tuning) methods. While in both situations we rely on measurements, a model is not employed in the latter case. Modelbased strategies are applicable if we are able to find a sufficiently good representation of our dynamical system and its actuation mechanisms. There is a long history of system identification techniques (Ljung 1999; 2010; Sjöberg et al. 1995) to identify models from data, which is revolutionized now with the rise of big data and machine learning. This does not necessarily mean only black-box models which are hard to analyze and do not provide physical intuition. In contrast, there has been increasing focus on developing techniques to infer parsimonious models that are interpretable and able to generalize beyond the data they have seen during the training stage (Bongard and Lipson 2007; Schmidt and Lipson 2009; Brunton et al. 2016; Duriez et al. 2016; Rudy et al. 2017). This is particularly useful for identifying low-complexity models for control. As cross-validation of models remains limited, i.e., models can only be evaluated on past observations of a single trajectory, the importance of identifying meaningful and interpretable models increases. Any successful control strategy relies on tractable models that are sufficiently low-dimensional so that the controller can compute the next control action and react sufficiently fast at relevant timescales. Unfortunately, in many systems, such as the spread of infectious diseases, financial trading or turbulence, we may not know the governing equations, or these may be too complex and high-dimensional to be used for the control task. Then, model-free methods are very useful and offer large potential.

A promising strategy for the control of the carbon-climate system could rely on both: (1) employing model-based control methods with simplified, low-dimensional models of the global carbon-climate system (e.g., IAM and ESM emulators) to improve our understanding of the system and to identify suitable control mechanisms that can then be incorporated in an expensive, high-dimensional (e.g., Kravitz et al. 2017a; MacMartin et al. 2017); and 
(2) developing model-free control strategies that rely heavily on observations. It is also worth noting that, in contrast to many engineering applications, the reaction time of the controller for the carbon-climate system is slow compared with technical response capabilities and available computing power. For instance, Jarvis et al. (2009) proposed a control strategy with a 20-year evaluation period for decision making, which is much longer than potential technical response times. Thus it is feasible to execute a model-based controller informed by realistic, high-dimensional models that can integrate IAMs and ESMs running on supercomputers.

\section{Stabilization of atmospheric $\mathrm{CO}_{2}$ as a congestion control problem}

The global carbon cycle can be conceptualized as a complex network of compartments that contain carbon in different chemical and physical forms. Carbon is exchanged among the different compartments or nodes of the network according to the capacity of natural sinks to take up carbon.

Since the beginning of the industrial period, as humans started to add $\mathrm{CO}_{2}$ to the atmosphere, the carbon stock in this compartment has increased. The main natural sinks, the oceans and the terrestrial biosphere, have absorbed a significant amount of this carbon, and their sink strength has increased proportionally with emissions, but not all extra carbon has been taken up by the natural sinks. Currently, it is estimated that natural sinks absorb about $43 \%$ of annual anthropogenic emissions, and about $45 \%$ accumulates in the atmosphere annually (Le Quéré et al. 2018; Friedlingstein et al. 2019).

If we conceptualize the global carbon system as a network of interconnected compartments, we can conceptualize carbon accumulation in the atmosphere as a congestion problem. Through fossil fuel combustions, humans inject carbon dioxide to the atmosphere and overwhelm the capacity of other nodes (surface ocean and terrestrial biosphere) to uptake all extra carbon, resulting in an accumulation of atmospheric $\mathrm{CO}_{2}$. The resulting warming, in combination with other global change factors (Canadell et al. 2007; Zaehle 2013), may decrease the carbon uptake capacity of the natural sinks, in turn reducing the throughput of the link to these compartments. This positive feedback is similar to traffic congestion where the accumulation of commuters in a certain area reduces the throughput and further increases the time they spend there, which further increases their number.

Congestion is a common problem in networks, which is well studied in communication networks (Low et al. 2002) and industrial manufacturing (Bastin 1999; Bastin and Guffens 2006). Systems of continuous-flow stirred-tank reactors, assembly lines and grinding machines are examples of mass-balanced systems that are susceptible to congestion when inflow demand exceeds the throughput capacity of the network. A suite of methods from control engineering provide general approaches to deal with congestion control in massbalanced systems (Bastin 1999), which due to their generality could be used to deal with the problem of avoiding congestion of carbon in the atmospheric compartment of the Earth system.

Bastin and Guffens (2006) showed that mass congestion in compartmental networks can be automatically prevented by using a nonlinear closed-loop controller that has a compartmental structure. This implies that carbon can be managed by designing and implementing a system of reservoirs that can temporarily store carbon to maximize throughput of the network by the natural carbon sinks. The controller can also be used to compute the amount of mass that is allowed to enter the network; therefore, it can be used to compute fossil fuel emission allowances. We believe this control mechanism can be used 
to exemplify the design of a global system for carbon management and climate change mitigation.

\section{Example: Computing fossil fuel emission allowances as a congestion-control problem}

To show the power of closed-loop control for managing the global carbon cycle, we use here an example inspired by the framework presented by Bastin and Guffens (2006), which attempts to avoid congestion in a compartmental network (Fig. 2). Specifically, we conceptualize the global carbon cycle as a system of compartments that transfer carbon among each other and ultimately release extra carbon to the deep ocean. Our objective is to avoid overflow of the atmospheric compartment as we add fossil fuel carbon. The natural sinks (terrestrial biosphere and surface ocean) exchange carbon with the atmosphere, but have a limited capacity on the rate to sequester and process this carbon. Therefore, we design a controller that tells us how much fossil fuel carbon is allowed to enter the atmosphere based on our ability to observe the behavior of the net flux between surface and deep ocean (Fig. 3). For simplicity, we exclude the temperature feedback from this example.

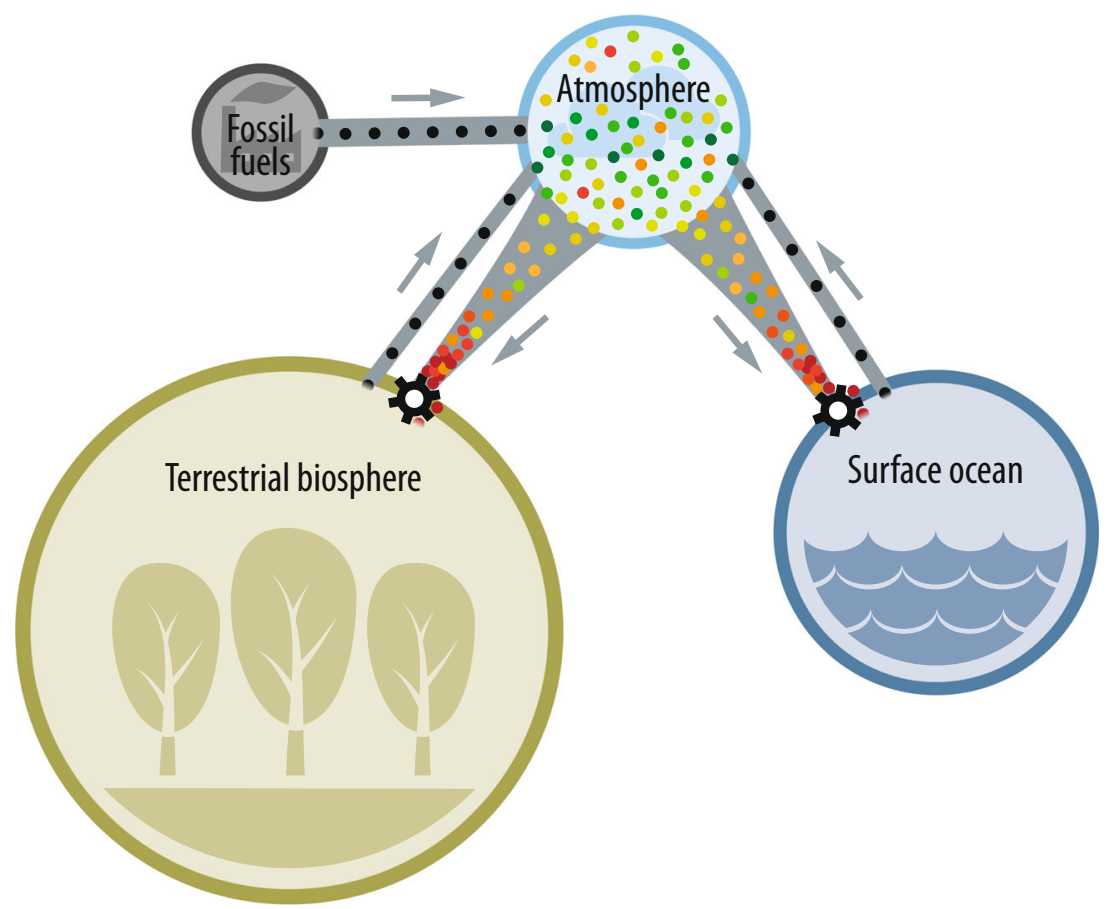

Fig. 2 Graphical representation of the concept of congestion in the global carbon cycle. As fossil fuels are added to the atmosphere, the terrestrial biosphere and the surface ocean can only take up extra carbon according to their natural sequestration capacity. Therefore, carbon dioxide accumulates in the atmosphere and results in congestion of molecules in the network. Congestion also leads to a longer time of $\mathrm{CO}_{2}$ molecules in the atmosphere, which is depicted by the color of the dots in the graphic. Green colors represent $\mathrm{CO}_{2}$ molecules that recently entered the atmosphere, while red colors represent molecules that have stayed for a longer time 


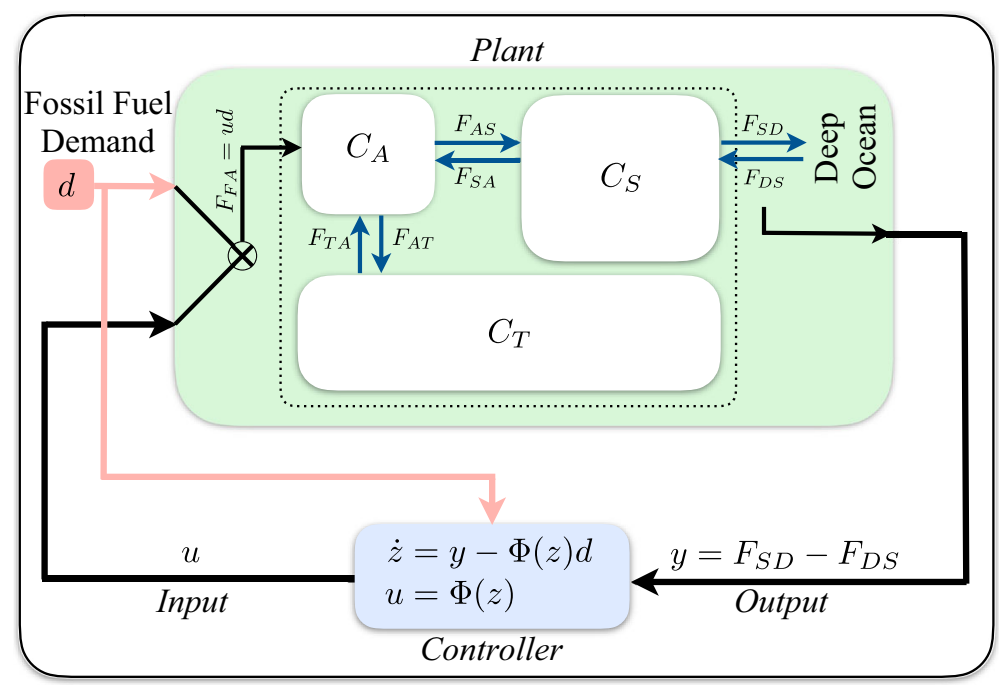

Fig. 3 Output feedback control scheme of a simple nonlinear global carbon-cycle model. The controller reacts to changes in the net flux out of the system and fossil fuel demand, producing an input signal $u$ that modifies the demand $d$

We consider a modified version of the simple nonlinear global carbon-cycle model introduced by Rodhe and Björkström (1979). It is depicted inside the dashed rectangle within the green box of Fig. 3 and consists of the three carbon compartments: atmosphere $\left(C_{A}\right)$, terrestrial biosphere $\left(C_{T}\right)$, and surface ocean $\left(C_{S}\right)$. A detailed description of the differential equations for each compartment is given in the Appendix.

In contrast to the original model of Rodhe and Björkström (1979), we assume that the directional fluxes between the atmosphere and the surface ocean and between the atmosphere and the terrestrial biosphere $\left(F_{A S}\right.$ and $\left.F_{A T}\right)$ saturate at 200 and $90 \mathrm{PgC} \mathrm{year}^{-1}$, respectively. This is consistent with the idea of saturation of natural sinks (Canadell et al. 2007; Le Quéré et al. 2008). The saturation of fluxes that remove carbon from the atmosphere potentially leads to an undesired accumulation of atmospheric carbon (Fig. 4a). This congestion can be avoided by controlling fossil fuel emissions, allowing a certain amount of emissions based on a known demand $d$.

Following Bastin and Guffens (2006), we implement an output feedback control scheme that avoids congestion by permitting only a fraction $\Phi$ of the demand $d$. To compute the fraction $\Phi$, we define an auxiliary variable $z$ by

$$
\dot{z}(t)=y(t)-\Phi(z(t)) \cdot d(t),
$$

where $y(t)=F_{S D}-F_{D S}$ denotes the net flux of carbon out of the system to the deep ocean. Intuitively, the variable $z$ can be thought of as the content of a virtual extra compartment that is fed by the net outflux $y(t)$ out of the system and drained by the controlled input $\Phi(z(t)) \cdot d(t)$, whose size depends on the content of the virtual pool via the monotonically increasing and continuously differentiable, but otherwise unconstrained function $\Phi$. Regardless of the specific choice of $\Phi$, this arrangement creates a virtual system that is physically closed, keeping the overall mass constant and therefore bounded, thus avoiding congestion. The freedom to choose $\Phi$ could, in a realistic scenario, be used to achieve additional goals apart from the main objective of congestion 
(a)

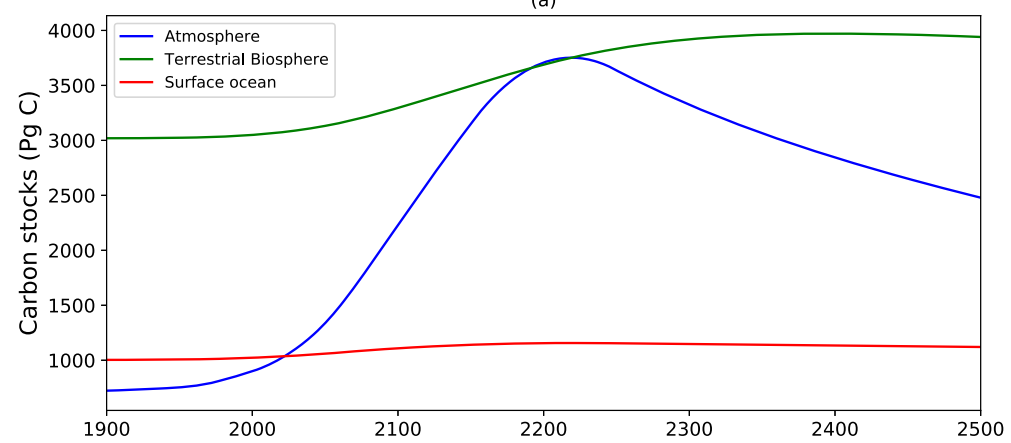

(b)

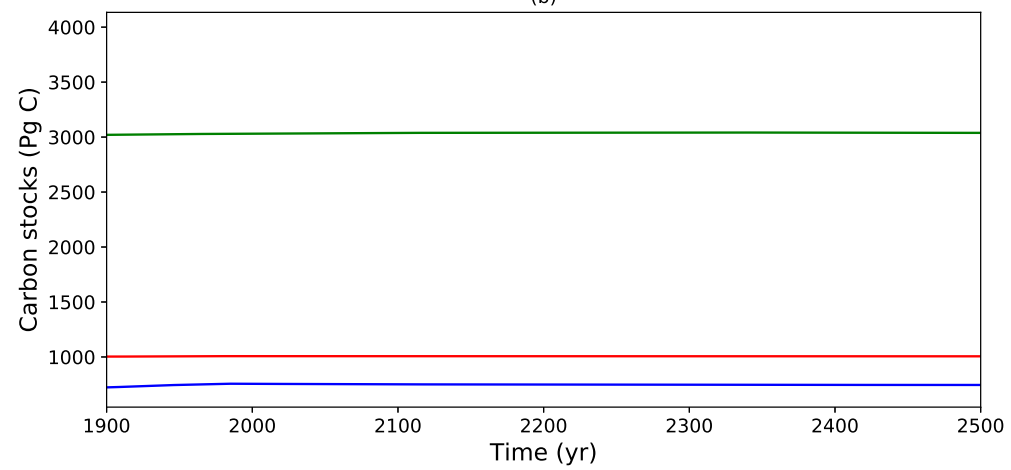

Fig. 4 a Response of carbon stocks in the atmosphere, terrestrial biosphere, and surface ocean, to the injection of fossil fuel according to the full demand; i.e., no control is applied. b Response of the carbon stocks when the closed-loop control is applied

control and could be optimized with respect to some desired properties. Such an optimization is clearly outside the scope of this example and would obscure our main objective to explain closed-loop control, which does not require any assumption of optimality. Our choice of $\Phi$ is therefore solely guided by simplicity and the desire to provide an intuitive way to affect the behavior of the controller. To this end, we create a family of functions $\Phi_{z_{\max }}$ parameterized for different values of a parameter $z_{\max }$ that represents the maximal size of the virtual compartment (see Appendix), and can be interpreted as the total amount of cumulative fossil fuel emissions allowed. With increasing $z_{\max }$ the controller acts more and more serenely. For decreasing values the reactions become faster and more restrictive.

For practical reasons, we assume here human fossil fuel demand $d(t)$ (Fig. 6) as equivalent to a high emission scenario (a combination of RCP8.5 and ECP8.5) (Fujino et al. 2006; Meinshausen et al. 2011), but acknowledge that actual demand may be very different in the future and can change unexpectedly from year to year. In fact, this control design does not rely on particular scenarios of fossil fuel emissions, only on short-term projections of demand that can be updated on a regular basis.

The function $u(t)=\Phi(z(t)) \in[0,1]$ controls the input $F_{F A}(t)=u(t) \cdot d(t) \leq d(t)$ of fossil fuel derived carbon to the system (see additional details about $\Phi(z(t))$ in the Appendix). By solving the extended system of equations that includes (5), we obtain the mapping $\mathscr{K}$ from observations $y(t)$ to action $u(t)$. 
(a)

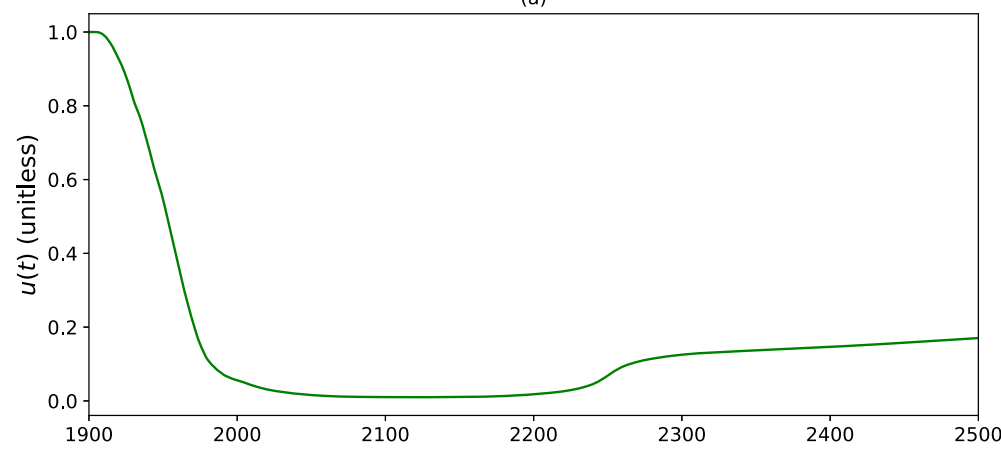

(b)

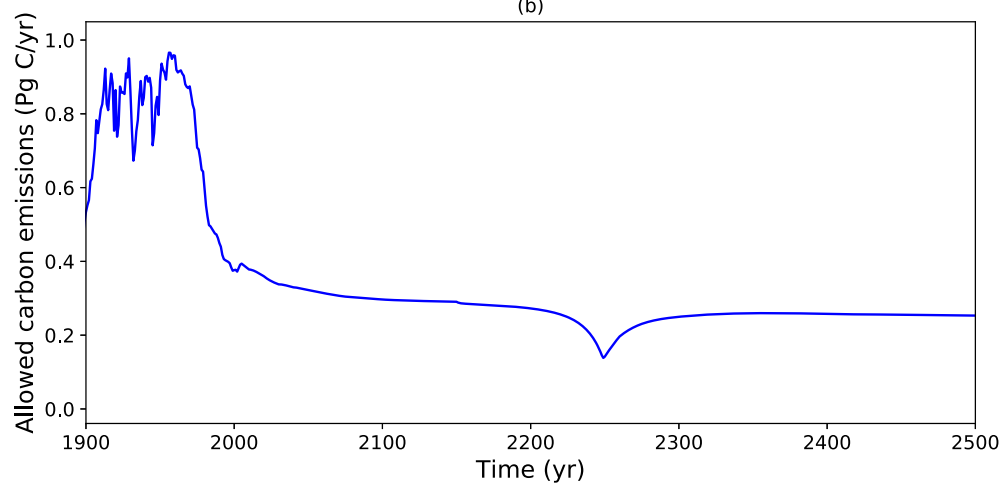

Fig. 5 Temporal evolution of the controller as it responds to fossil fuel emission demands and observations of the net flux out of the system. a Strength of the control action as quantified by $u(t)$ (unitless). b Allowed carbon emissions over time as quantified by the control input $F_{F A}(t)=u(t) \cdot d(t)$

This control mechanism effectively keeps atmospheric carbon to near constant values for historical levels of demand consistent with actual emissions (Fig. 4b). The degree of action $u$, which sets the proportional constraint on the demand $(u=1$ : all demand is allowed, $u=0$ : no emissions allowed), changed rapidly over time reaching a maximum strength by the end of the twenty-first century (Fig. 5a), suggesting that policies must adapt quickly according to fast changes in the demand. Furthermore, the controller did allow for fossil fuel emissions every year, particularly during the twentieth century, but limited emissions later on as the demand increased and the capacity of the natural sinks reached their maximum (Fig. 5b).

Albeit simple, the example is valuable since it shows the following: (1) Closed-loop control provides the conceptual and mathematical tools to effectively steer the global carbon cycle while considering its internal nonlinear structure. No assumptions of linearity were made, nor was the system linearized at a point. (2) Instead of providing a scenario that society should follow, closed-loop control provides a rule that uses observations to quickly adapt to changing conditions such as rapid changes in fossil fuel demand. (3) The design of the controller has important implications for the monitoring system that should be deployed. In this example, the monitoring infrastructure must measure or reconstruct the exchange of carbon between the surface and the deep ocean, but for other control designs this requirement may be different. Obviously, other controllers can be designed not only to set limits 


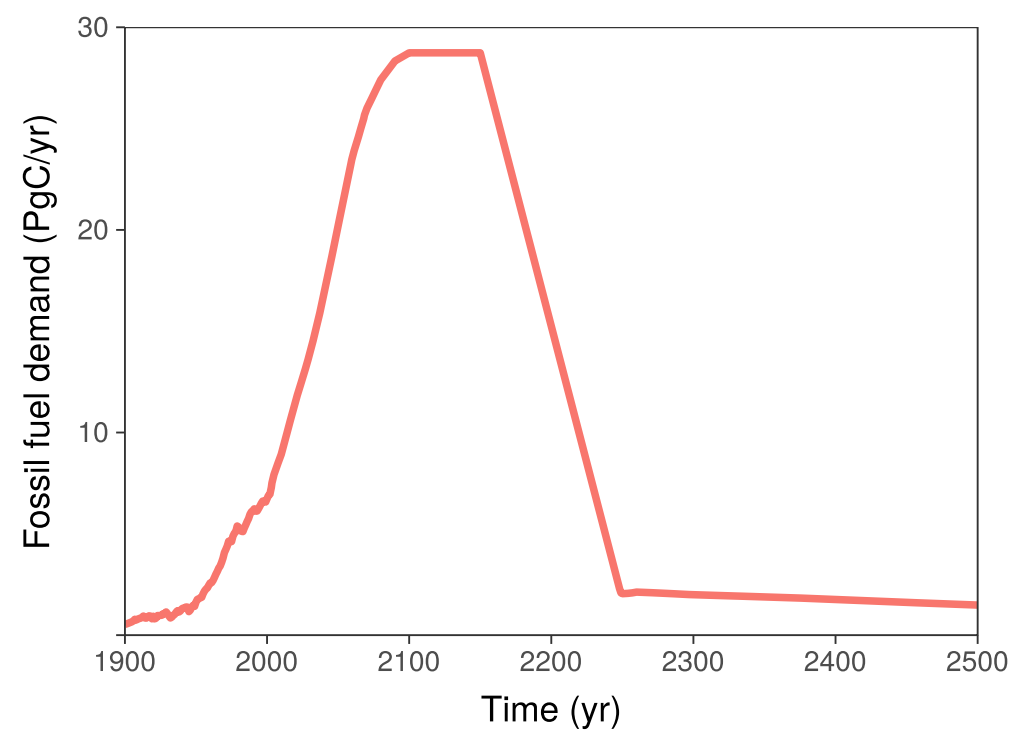

Fig. 6 Historical and projected human demand $d$ for fossil fuel consumption. This demand represents the potential inputs of carbon to the atmosphere in the absence of a controller. It is constructed by merging RCP8.5 and ECP8.5 emission scenarios (Fujino et al. 2006; Meinshausen et al. 2011)

on carbon emissions but also to remove carbon through sequestration in geological or biological sinks. More realistic models and better knowledge on the demand for fossil fuel emissions can provide additional insights on how to steer the global carbon-climate system to a particular state.

\section{Conclusions}

The problem of steering Earth's carbon-climate system to a desired state can be posed as a closed-loop control problem that continuously adapts action according to measurements and uncertainty in the dynamic behavior of the system. We provided here a general mathematical description of the carbon-climate system that can be used to formally treat the closed-loop control problem. This representation takes advantage of the compartmental structure of the global carbon system, which imposes specific mathematical restrictions on the system of equations that lead to particular properties such as dynamic stability.

In particular, $\mathrm{CO}_{2}$ levels in the atmosphere can be effectively controlled using concepts and tools from congestion control of networks. Control theory provides concepts and methods that we could potentially use to steer the global carbon-climate system away from dangerous climate change, and limit temperature increase according to the targets of the Paris Agreement. For this purpose, management of the global carbon cycle can be used as an effective approach to control global temperature change.

Particularly important for addressing the control problem of the global carbon-climate system are the dual topics of observability and controllability. For the design of effective control mechanisms (controllers), an observatory system that monitors and reconstructs the time-evolution of the state of the system is required. This means that a global carbon monitoring system that makes information available at relevant timescales is key for the design 
of control mechanisms that can lead to rapid policy action. In this sense, the formal definition of the control problem can potentially help to devise the type of institutions and infrastructure that would be needed to steer the global carbon-climate system.

Our simple example showed that the global carbon cycle could be effectively managed by having knowledge on fossil fuel demand and the capacity of the system to transfer carbon to geological reservoirs such as the deep ocean. We obtained a mathematical rule that prescribes actions based on changes in the demand and the internal dynamics of the system, so this rule can be used for adaptive management of the carbon cycle. This approach differs from scenario-based prescriptions of emission pathways and could be very useful for policy decisions on shorter time horizons than those imposed by long-term scenarios.

\section{Appendix}

\section{A.1 Detailed model description}

The model consists of three carbon compartments: atmosphere $\left(C_{A}\right)$, terrestrial biosphere $\left(C_{T}\right)$, and surface ocean $\left(C_{S}\right)$. The letters $D$ and $F$ stand for the external compartments deep ocean and fossil fuel reserves. The carbon contents of the compartments are always given in units of $\mathrm{PgC}$ and fluxes in units of $\mathrm{PgC}$ year $^{-1}$. Two external fluxes add carbon to the system. The first one, $F_{D S}$, is constant and goes from the deep ocean to the surface ocean, whereas the second one, $F_{F A}=F_{F A}(t)$, is time dependent and represents carbon added to the atmosphere by the burning of fossil fuels. It is defined by $F_{F A}=u d$ with $u$ being the control input and $d$ being the human demand for fossil fuels (Fig. 6). Carbon can leave the system only if it moves from the surface ocean to the deep ocean. We denote this flux by $F_{S D}$.

A flux from compartment $X$ to compartment $Y$ is denoted by $F_{X Y}$ and the following fluxes exist in the model, all given in $\mathrm{PgC}_{\text {ear }}{ }^{-1}$ :

$$
\begin{array}{ll}
F_{A T}=60\left(C_{A} / 700\right)^{\alpha}, & F_{A S}=100 C_{A} / 700, \\
F_{T A}=60 C_{T} / 3000, & F_{S A}=100\left(C_{S} / 1000\right)^{\beta}, \\
F_{S D}=45 C_{S} / 1000, & F_{D S}=45 .
\end{array}
$$

The two parameters $\alpha=0.2$ and $\beta=10.0$ control the fluxes from the atmosphere to the terrestrial biosphere and from the surface ocean to the atmosphere, respectively.

The model can now be described by the three ordinary differential equations, for $t>$ $t_{0}=1765$,

$$
\begin{aligned}
\frac{\mathrm{d}}{\mathrm{d} t} C_{A} & =F_{T A}+F_{S A}-F_{A T}-F_{A S}+F_{F A}(t), \\
\frac{\mathrm{d}}{\mathrm{d} t} C_{T} & =F_{A T}-F_{T A}, \\
\frac{\mathrm{d}}{\mathrm{d} t} C_{S} & =F_{A S}-F_{S A}-F_{S D}+F_{D S} .
\end{aligned}
$$

Note that the right-hand side of (7) depends through (6) not only on $t$ but also on the state vector $C(t)=\left(C_{A}(t), C_{T}(t), C_{S}(t)\right)^{T}$. Therefore, fluxes among compartments respond nonlinearly to their respective contents. If we now define the state- and time-dependent compartmental matrix $\mathbf{B}=\mathbf{B}(C, t)$ to equal 


$$
\left(\begin{array}{ccc}
-C_{A}^{-1}\left(F_{A T}+F_{A S}\right) & C_{T}^{-1} F_{T A} & C_{S}^{-1} F_{S A} \\
C_{A}^{-1} F_{A T} & -C_{T}^{-1} F_{T A} & 0 \\
C_{A}^{-1} F_{A S} & 0 & -C_{S}^{-1}\left(F_{S A}+F_{S D}\right)
\end{array}\right)
$$

and $s(t):=\left(F_{F A}(t), 0, F_{D S}\right)^{T}$, then the model fits in the framework of (1) without the temperature component. We can then write the nonlinear time-dependent compartmental system as

$$
\begin{aligned}
\frac{\mathrm{d}}{\mathrm{d} t} C & =\mathbf{B}(C, t) C+s(t), \quad t>t_{0}, \\
C\left(t_{0}\right) & =C_{0} .
\end{aligned}
$$

We ran the uncontrolled system $(u=1)$ from its equilibrium point $C_{0}=$ $(700,3000,1000)^{T}$ from 1765 forward until 1900, and after this, we activated the control function $u(t)=\Phi(z(t))$. In other words, we allowed all fossil fuel emissions until the year 1900 , and after this year, we assumed humanity controlled the global carbon cycle.

\section{A.2 The control function $u(t)=\Phi(z(t))$}

The closed-loop controller proposed by Bastin and Guffens (2006) has as control objective to match the fossil fuel demand as best as possible while avoiding overflows of the compartmental network. For the simple case of one single output, it is defined as $u(t)=\Phi(z(t))$, where the function $\Phi: \mathbb{R}^{+} \mapsto \mathbb{R}^{+}$can be chosen freely as long as it is monotonically increasing, continuously differentiable and fulfills $\Phi(0)=0$ as well as $\lim _{z \rightarrow \infty} \Phi(z)=1$. This freedom could be used to optimize the controller, e.g., by introducing a parameterization of $\Phi$ with many tunable parameters. Since we were instead interested in maximal simplicity we chose a representation that depends only on the initial value $z_{0}=z_{\max }$, the size of the imaginary buffer. Furthermore, we wanted the controller to set in smoothly. This has been achieved by choosing $\Phi(z)=1$ for $z \geq z_{\max }$. In this way, the controller is inactive

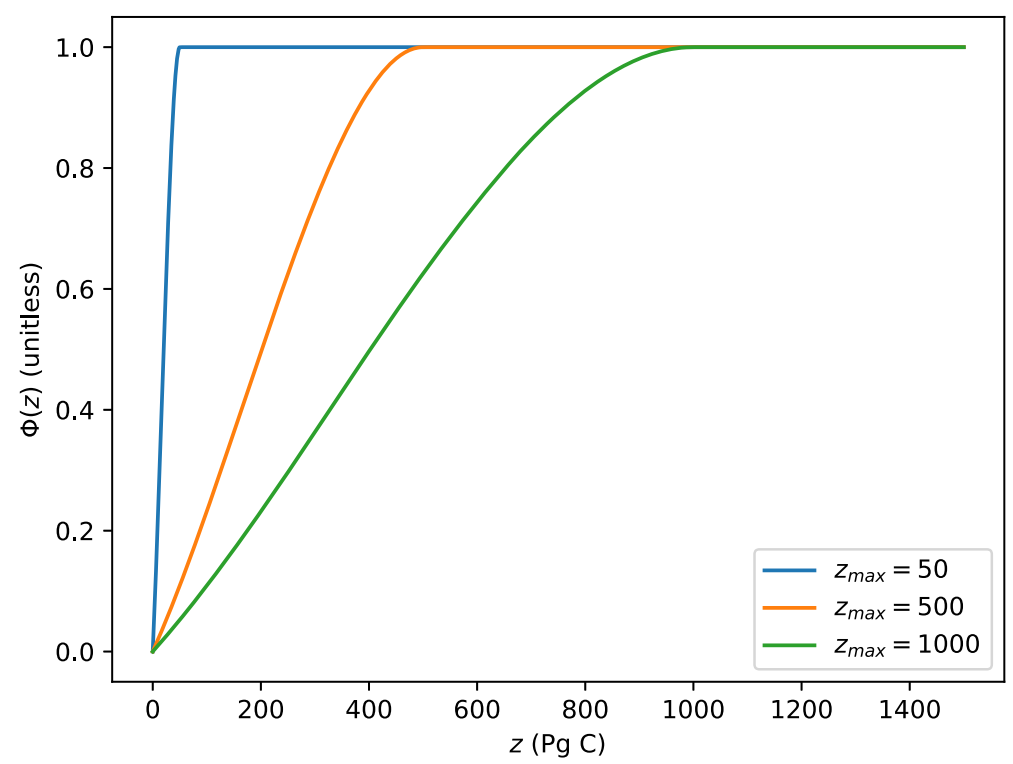

Fig. 7 Comparison of the different forms of the control function $\Phi(z)$ for different values of $z_{\max }$ 
as long as the buffer pool is empty and has full capacity $z_{0}=z_{\max }$, but sets in smoothly as soon as the buffer fills and the remaining storage $z$ decreases.

The mathematical form of the control function chosen for the example can then be expressed as

$$
\Phi(z)= \begin{cases}f & z \leq z_{\max }, \\ 1 & z>z_{\max }\end{cases}
$$

with $f$ following the requirements

$$
\left\{\begin{array}{l}
f(0)=0, \\
f\left(z_{\max }\right)=1, \\
f^{\prime}(0)=1 / z_{\max }, \\
f^{\prime}\left(z_{\max }\right)=0,
\end{array}\right.
$$

which can be fulfilled by a cubic Hermite spline, in which case they uniquely determine the coefficients of the cubic function

$$
f(z)=a_{0}+a_{1} z_{1}+a_{2} z^{2}+a_{3} z^{3} .
$$

The controller therefore depends only on the argument $z_{\max }$, which determines not only the value at which the controller switches off but also the speed (first derivative) at which it operates.
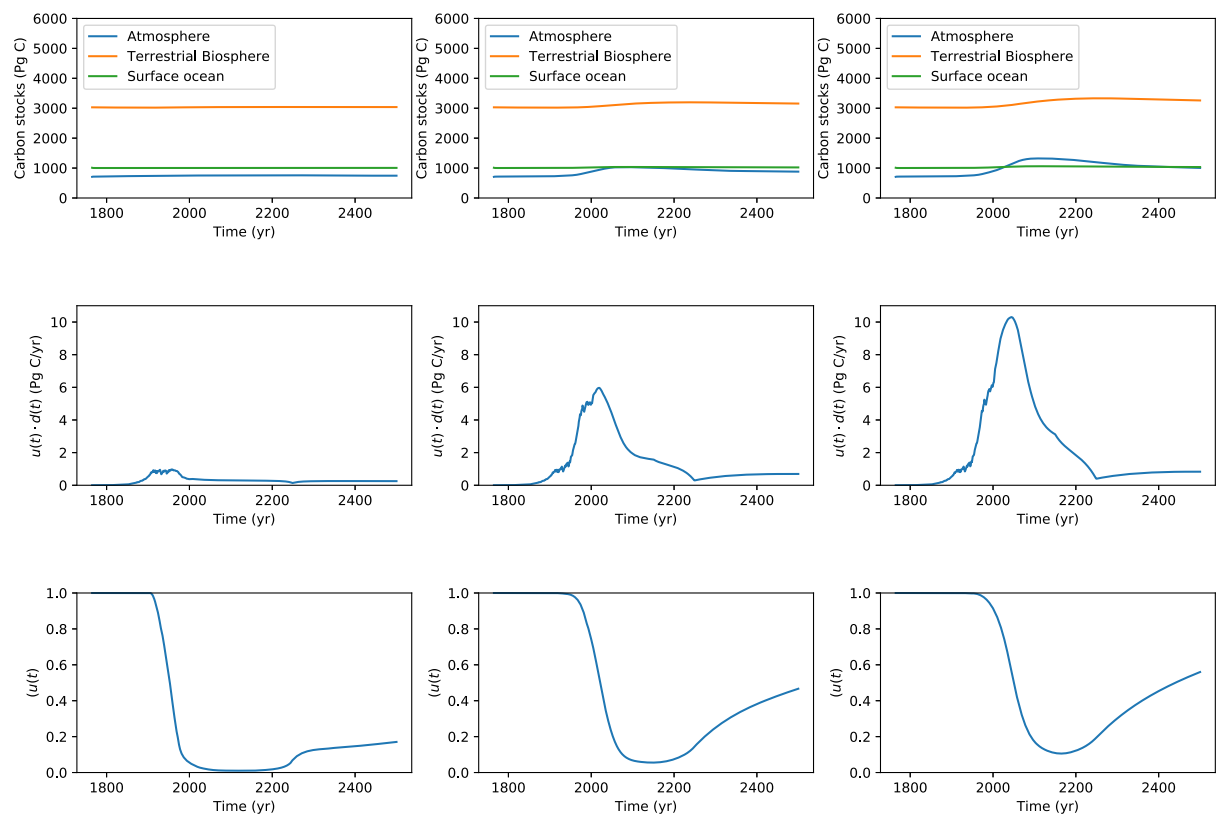

Fig. 8 Effect of different values of $z_{\max }$ on the control mechanism and its effectiveness at avoiding accumulation of carbon in the atmosphere. Values of $z_{\max }$ correspond to 50 (left panels), 500 (middle panels), and 1000 (right panels) PgC. Top panels show the time evolution of the total amount of carbon stored in the atmosphere, terrestrial biosphere, and surface ocean compartments. Middle row panels show the allowed amount of carbon emissions in $\mathrm{PgC}$ year ${ }^{-1}$ as quantified by $F_{F A}(t)=u(t) \cdot d(t)$. Lower panels show the strength of the control as quantified by $u(t)$, with $u(t)=0$ representing full action and no emissions allowed, and $u(t)=1$ representing no action and all emission demand allowed 
To illustrate the effect of the parameter $z_{\max }$ on the controller, we present in Fig. 7 the shape of $\Phi(z)$ for values of $z_{\max } \in\{50,500,1000\} \mathrm{PgC}$. For small values of $z_{\max }$ the controller has a steep slope, which means that it can react fast, while for larger values of the parameter the controller reacts slowly (Fig. 8). In fact, for $z_{\max }=1000$ the controller cannot effectively avoid congestion of the network, leading to undesired accumulation of carbon in the atmosphere. The example presented in the main text corresponds to $z_{\max }=50$.

Acknowledgments Funding was provided by the German Research Foundation (Emmy-Noether Programme, SI 1953/2-2) and the Max Planck Society. EK gratefully acknowledges generous support by the Washington Research Foundation, Moore Foundation (Award \#2013-10-29), Sloan Foundation (Award \#3835), University of Washington eScience Institute, and the Mistletoe Foundation.

Funding Open Access funding enabled and organized by Projekt DEAL.

Open Access This article is licensed under a Creative Commons Attribution 4.0 International License, which permits use, sharing, adaptation, distribution and reproduction in any medium or format, as long as you give appropriate credit to the original author(s) and the source, provide a link to the Creative Commons licence, and indicate if changes were made. The images or other third party material in this article are included in the article's Creative Commons licence, unless indicated otherwise in a credit line to the material. If material is not included in the article's Creative Commons licence and your intended use is not permitted by statutory regulation or exceeds the permitted use, you will need to obtain permission directly from the copyright holder. To view a copy of this licence, visit http://creativecommonshorg/licenses/by/4.0/.

\section{References}

Ackerman F, DeCanio SJ, Howarth RB, Sheeran K (2009) Limitations of integrated assessment models of climate change. Clim Change 95(3):297-315

Anderies JM, Rodriguez AA, Janssen MA, Cifdaloz O (2007) Panaceas, uncertainty, and the robust control framework in sustainability science. Proc Natl Acad Sci 104(39):15194-15199

Anderson DH (1983) Compartmental modeling and tracer kinetics, vol 50. Springer Science \& Business Media, Berlin

Aström KJ, Murray RM (2010) Feedback systems: an introduction for scientists and engineers. Princeton university press, Princeton

Åström KJ, Wittenmark B (2013) Adaptive control. Courier Corporation, North Chelmsford

Bastin G (1999) Issues in modelling and control of mass balance systems. In: Aeyels D, LamnabhiLagarrigue F, van der Schaft A (eds) Stability and stabilization of nonlinear systems. Springer London, London, 53-74

Bastin G, Guffens V (2006) Congestion control in compartmental network systems. Syst Control Lett 55(8):689-696

Bastin G, Praly L (1999) Feedback stabilisation with positive control of a class of dissipative mass-balance systems. IFAC Proc Vol 32(2):1096-1100

Bonetti F, McInnes C (2018) Multiple input control strategies for robust and adaptive climate engineering in a low-order 3-box model, vol 474, p 20180447

Bongard J, Lipson H (2007) Automated reverse engineering of nonlinear dynamical systems. Proc Natl Acad Sciences 104(24):9943-9948

Brunton SL, Proctor JL, Kutz JN (2016) Discovering governing equations from data by sparse identification of nonlinear dynamical systems. Proc Natl Acad Sci 113(15):3932-3937

Caldeira K, Bala G, Cao L (2013) The science of geoengineering. Annu Rev Earth Planet Sci 41(1):231-256

Camacho EF, Alba CB (2013) Model predictive control. Springer, Berlin

Canadell JG, Pataki D, Gifford R, Houghton RA, Luo Y, Raupach M, Smith P, Steffen W (2007) Saturation of the terrestrial carbon sink. The IGBP Series. Springer, Berlin, pp 59-78

Cao L, Jiang J (2017) Simulated effect of carbon cycle feedback on climate response to solar geoengineering. Geophys Res Lett 44(24):12,484-12,491 
Collins WD, Craig A, Truesdale J, Di Vittorio AV, Jones AD, Bond-Lamberty B, Calvin K, Edmonds J, Kim SH, Thomson A, Patel P, Zhou Y, Mao J, Shi X, Thornton PE, Chini L, Hurtt G (2015) The integrated earth system model version 1: formulation and functionality. Geosci Model Dev 8(7):2203-2219

Cox PM, Huntingford C, Williamson MS (2018) Emergent constraint on equilibrium climate sensitivity from global temperature variability. Nature 553:319 EP -

Duriez T, Brunton SL, Noack BR (2016) Machine learning control, taming nonlinear dynamics and turbulence. Springer, Berlin

Fleming PJ, Purshouse RC (2002) Evolutionary algorithms in control systems engineering: a survey. Control Eng Pract 10(11):1223-1241

Fredriksen H-B, Rypdal M (2017) Long-range persistence in global surface temperatures explained by linear multibox energy balance models. J Climate 30(18):7157-7168

Friedlingstein P, Jones MW, O’Sullivan M, Andrew RM, Hauck J, Peters GP, Peters W, Pongratz J, Sitch S, Le Quéré C, Bakker DCE, Canadell JG, Ciais P, Jackson RB, Anthoni P, Barbero L, Bastos A, Bastrikov V, Becker M, Bopp L, Buitenhuis E, Chandra N, Chevallier F, Chini L, Currie KI, Feely RA, Gehlen M, Gilfillan D, Gkritzalis T, Goll DS, Gruber N, Gutekunst S, Harris I, Haverd V, Houghton RA, Hurtt G, Ilyina T, Jain AK, Joetzjer E, Kaplan JO, Kato E, Klein Goldewijk K, Korsbakken JI, Landschützer P, Lauvset SK, Lefèvre N, Lenton A, Lienert S, Lombardozzi D, Marland G, McGuire PC, Melton JR, Metzl N, Munro DR, Nabel JEMS, Nakaoka S-I, Neill C, Omar AM, Ono T, Peregon A, Pierrot D, Poulter B, Rehder G, Resplandy L, Robertson E, Rödenbeck C, Séférian R, Schwinger J, Smith N, Tans PP, Tian H, Tilbrook B, Tubiello FN, van der Werf GR, Wiltshire AJ, Zaehle S (2019) Global carbon budget 2019. Earth Syst Sci Data 11(4):1783-1838

Friedlingstein P, Meinshausen M, Arora VK, Jones CD, Anav A, Liddicoat SK, Knutti R (2014) Uncertainties in CMIP5 climate projections due to carbon cycle feedbacks. J Clim 27(2):511-526

Fujino J, Nair R, Kainuma M, Masui T, Matsuoka Y (2006) Multi-gas mitigation analysis on stabilization scenarios using AIM global model. Energy J 343-353

Hasselmann K (1976) Stochastic climate models part i. theory. Tellus 28(6):473-485

IPCC (2018) Global warming of $1.5^{\circ} \mathrm{C}$. Technical report, World Meteorological Organization

Jackson LS, Crook JA, Jarvis A, Leedal D, Ridgwell A, Vaughan N, Forster PM (2015) Assessing the controllability of arctic sea ice extent by sulfate aerosol geoengineering. Geophys Res Lett 42(4):1223-1231

Jacquez JA, Simon CP (1993) Qualitative theory of compartmental systems. SIAM Rev 35(1):43-79

Jarvis A, Leedal D, Taylor CJ, Young P (2009) Stabilizing global mean surface temperature: A feedback control perspective. Environ Model Softw 24(5):665-674

Jarvis A, Young PC, Leedal DT, Chotai A (2008) A robust sequential co2 emissions strategy based on optimal control of atmospheric co2 concentrations. Clim Change 86(3):357-373

Kaiser E, Kutz JN, Brunton SL (2018) Sparse identification of nonlinear dynamics for model predictive control in the low-data limit. Proc R Soc A 474(2219):20180335

Kalman R, Ho Y, Narendra K (1963) Controllability of linear dynamical systems. Contr Diff Eqs 1:189-213

Khalil HK (1996) Noninear systems. Prentice-Hall, New Jersey

Knutti R, Rugenstein MAA, Hegerl GC (2017) Beyond equilibrium climate sensitivity. Nat Geosci 10(10):727-736

Kravitz B, MacMartin DG, Leedal DT, Rasch PJ, Jarvis A (2014) Explicit feedback and the management of uncertainty in meeting climate objectives with solar geoengineering. Environ Res Lett 9(4):044006

Kravitz B, MacMartin DG, Mills MJ, Richter JH, Tilmes S, Lamarque J-F, Tribbia JJ, Vitt F (2017a) First simulations of designing stratospheric sulfate aerosol geoengineering to meet multiple simultaneous climate objectives. J Geophys Res Atmos 122(23):12,616-12,634

Kravitz B, MacMartin DG, Rasch PJ, Wang H (2017b) Technical note: simultaneous fully dynamic characterization of multiple input-output relationships in climate models. Atmos Chem Phys 17(4):2525-2541

Kravitz B, MacMartin DG, Wang H, Rasch PJ (2016) Geoengineering as a design problem. Earth Syst Dyn 7(2):469-497

Le Quéré C, Andrew RM, Friedlingstein P, Sitch S, Hauck J, Pongratz J, Pickers PA, Korsbakken JI, Peters GP, Canadell JG, Arneth A, Arora VK, Barbero L, Bastos A, Bopp L, Chevallier F, Chini L, Ciais P, Doney SC, Gkritzalis T, Goll DS, Harris I, Haverd V, Hoffman FM, Hoppema M, Houghton RA, Hurtt G, Ilyina T, Jain AK, Johannessen T, Jones CD, Kato E, Keeling RF, Goldewijk KK, Landschützer P, Lefèvre N, Lienert S, Liu Z, Lombardozzi D, Metzl N, Munro DR, Nabel JEMS, Nakaoka S-I, Neill C, Olsen A, Ono T, Patra P, Peregon A, Peters W, Peylin P, Pfeil B, Pierrot D, Poulter B, Rehder G, Resplandy L, Robertson E, Rocher M, Rödenbeck C, Schuster U, Schwinger J, Séférian R, Skjelvan I, Steinhoff T, Sutton A, Tans PP, Tian H, Tilbrook B, Tubiello FN, van der Laan-Luijkx IT, van der Werf GR, Viovy N, Walker AP, Wiltshire AJ, Wright R, Zaehle S, Zheng B (2018) Global carbon budget 2018. Earth Syst Sci Data 10(4):2141-2194 
Le Quéré C, Rödenbeck C, Buitenhuis ET, Conway TJ, Langenfelds R, Gomez A, Labuschagne C, Ramonet M, Nakazawa T, Metzl N, Gillett NP, Heimann M (2008) Response to comments on saturation of the southern ocean $\mathrm{CO}_{2}$ sink due to recent climate change. Science 319(5863):570

Levin S, Xepapadeas T, Crépin A-S, Norberg J, de Zeeuw A, Folke C, Hughes T, Arrow K, Barrett S, Daily G, Ehrlich P, Kautsky N, Mäler K-G, Polasky S, Troell M, Vincent JR, Walker B (2013) Socialecological systems as complex adaptive systems: modeling and policy implications. Environ Dev Econ 18(2):111-132

Ljung L (1999) System identification: theory for the user. Prentice Hall, Upper Saddle River

Ljung L (2010) Perspectives on system identification. Annu Rev Control 34(1):1-12

Long JCS, Shepherd JG (2014) The strategic value of geoengineering research. In: Freedman B. (ed) Global environmental change. Springer Netherlands, Dordrecht, pp 757-770

Low SH, Paganini F, Doyle JC (2002) Internet congestion control. IEEE Control Syst Mag 22(1):28-43

MacMartin DG, Caldeira K, Keith DW (2014a) Solar geoengineering to limit the rate of temperature change. Philos Trans A Math Phys Eng Sci 372(2031):20140134

MacMartin DG, Kravitz B (2019) The engineering of climate engineering. Ann Rev Control Robot Auton Syst 2(1):445-467

MacMartin DG, Kravitz B, Keith DW, Jarvis A (2014b) Dynamics of the coupled human-climate system resulting from closed-loop control of solar geoengineering. Clim Dyn 43(1):243-258

MacMartin DG, Kravitz B, Tilmes S, Richter JH, Mills MJ, Lamarque J-F, Tribbia JJ, Vitt F (2017) The climate response to stratospheric aerosol geoengineering can be tailored using multiple injection locations. J Geophys Res Atmos 122(23):12,574-12,590

Matthews HD, Caldeira K (2008) Stabilizing climate requires near-zero emissions. Geophys Res Lett 35(4)

Mayne DQ, Rawlings JB, Rao CV, Scokaert POM (2000) Constrained model predictive control: Stability and optimality. Automatica 36(6):789-814

Meinshausen M, Smith SJ, Calvin K, Daniel JS, Kainuma M, Lamarque J, Matsumoto K, Montzka S, Raper S, Riahi K et al (2011) The RCP greenhouse gas concentrations and their extensions from 1765 to 2300. Clim Change 109(1-2):213

Metzler H, Müller M, Sierra CA (2018) Transit-time and age distributions for nonlinear time-dependent compartmental systems. Proc Natl Acad Sci 115(6):1150-1155

Morgan MG, Keith DW (2008) Improving the way we think about projecting future energy use and emissions of carbon dioxide. Clim Change 90(3):189-215

Nordhaus WD (1975) Can we control carbon dioxide? Technical Report WP-75-063, IIASA

Ogata K, Yang Y (2002) Modern control engineering, vol 4. Prentice hall India, Patparganj

Pacala S, Socolow R (2004) Stabilization wedges: Solving the climate problem for the next 50 years with current technologies. Science 305(5686):968-972

Raupach MR (2013) The exponential eigenmodes of the carbon-climate system, and their implications for ratios of responses to forcings. Earth Syst Dyn 4(1):31-49

Rodhe H, Björkström A (1979) Some consequences of non-proportionality between fluxes and reservoir contents in natural systems. Tellus 31(3):269-278

Rudy SH, Brunton SL, Proctor JL, Kutz JN (2017) Data-driven discovery of partial differential equations. Science Adv 3:e1602614

Sastry SS (2013) Nonlinear systems: analysis, stability, and control, vol 10. Springer, Berlin

Schellnhuber H-J, Kropp J (1998) Geocybernetics: controlling a complex dynamical system under uncertainty. Naturwissenschaften 85(9):411-425

Schmidt M, Lipson H (2009) Distilling free-form natural laws from experimental data. Science 324(5923):81-85

Shamma JS, Athans M (1990) Analysis of gain scheduled control for nonlinear plants. IEEE Trans Autom Contr 35(8):898-907

Sierra CA, Ceballos-Núñez V, Metzler H, Müller M. (2018) Representing and understanding the carbon cycle using the theory of compartmental dynamical systems. J Adv Model Earth Syst 10(8):1729-1734

Sjöberg J, Zhang Q, Ljung L, Benveniste A, Delyon B, Glorennec P-Y, Hjalmarsson H, Juditsky A (1995) Nonlinear black-box modeling in system identification: a unified overview. Automatica 31(12):16911724

Skogestad S (2007) Multivariable feedback control: analysis and design. Wiley, New York

Sontag ED (1998) Mathematical control theory: deterministic finite dimensional systems. Springer, New York

Steffen W, Rockström J, Richardson K, Lenton TM, Folke C, Liverman D, Summerhayes CP, Barnosky AD, Cornell SE, Crucifix M, Donges JF, Fetzer I, Lade SJ, Scheffer M, Winkelmann R, Schellnhuber HJ (2018) Trajectories of the earth system in the anthropocene. Proc Natl Acad Sci 115(33):82528259 
Stengel RF (2012) Optimal control and estimation. Courier Corporation, Chelmsford

Sundquist ET, Ackerman KV, Parker L, Huntzinger DN (2013) An introduction to global carbon cycle management. In: Mcpherson BJ, Sundquist ET (eds) Carbon sequestration and its role in the global carbon cycle. American Geophysical Union (AGU), pp 1-23

Sutton RS, Barto AG (2018) Reinforcement learning: an introduction. MIT press, Cambridge

Thornton PE, Calvin K, Jones AD, Di Vittorio AV, Bond-Lamberty B, Chini L, Shi X, Mao J, Collins WD, Edmonds J, Thomson A, Truesdale J, Craig A, Branstetter ML, Hurtt G (2017) Biospheric feedback effects in a synchronously coupled model of human and earth systems. Nat Clim Change 7(7):496-500

Vardas G, Xepapadeas A (2010) Model uncertainty, ambiguity and the precautionary principle: Implications for biodiversity management. Environ Resour Econ 45(3):379-404

Walters CJ, Hilborn R (1978) Ecological optimization and adaptive management. Annu Rev Ecol Syst 9(1):157-188

Weatherhead EC, Wielicki BA, Ramaswamy V, Ackerman MATP, Atlas R, Brasseur G, Bruhwiler L, Busalacchi AJ, Butler JH, Clack CTM, Cooke R, Cucurull L, Davis SM, English JM, Fahey DW, Fine SS, Liang JKLS, Loeb NG, Rignot E, Soden B, Stanitski D, Stephens G, Tapley BD, Thompson AM, Trenberth KE, Wuebbles D (2018) Designing the climate observing system of the future. Advancing Earth and Space Science 6(1):80-102

Weyant J (2017) Some contributions of integrated assessment models of global climate change. Rev Environ Econ Policy 11(1):115-137

Zaehle S (2013) Terrestrial nitrogen-carbon cycle interactions at the global scale. Philos Trans R Soc Lond B Biol Sci 368(1621):20130125

Zhang C, Ordóñez R (2012) Extremum-seeking control and applications: a numerical optimization-based approach. Springer, London

Publisher's note Springer Nature remains neutral with regard to jurisdictional claims in published maps and institutional affiliations. 